\title{
Supervisors, Food Preparation and Serving Workers
}

National Cancer Institute

\section{Source}

National Cancer Institute. Supervisors, Food Preparation and Serving Workers. NCI

Thesaurus. Code C122517.

Workers who directly supervise and coordinate activities of workers eng aged in preparing and serving food. 